\title{
BEM-ESTAR NA ABORDAGEM DAS CAPACITAÇÕES E NA ECONOMIA FEMINISTA: ALGUMA COMPLEMENTARIDADE?
}

\author{
Well-being in the Capabilities Approach and Feminist Economics: any \\ complementarity?
}

\author{
Mayara da Mata Moraes \\ Graduanda em Ciências Econômicas \\ Universidade Federal de Santa Catarina, Florianópolis-SC, Brasil \\ mayara.m.moraes@grad.ufsc.br \\ Solange Marin \\ Professora do Departamento de Economia e Relações Internacionais da Universidade Federal de Santa Catarina \\ Universidade Federal de Santa Catarina, Florianópolis-SC, Brasil \\ solange.marin@ufsc.br
}

\begin{abstract}
RESUMO
Por meio de uma revisão de literatura, o presente trabalho almeja interpelar o debate econômico sobre o conceito de bemestar fornecendo paralelos entre o entendimento da Abordagem das Capacitações de Amartya Sen com o da economia feminista, bem como contrapô-los com a definição da teoria econômica neoclássica. Segundo os pressupostos dessa última, o bem-estar é visto como a satisfação de preferências e avaliado segundo o critério de eficiência de Pareto. Em oposição a essa perspectiva, a Abordagem das Capacitações conceitua bem-estar como uma questão do que os sujeitos são capazes de ser e de fazer e, consequentemente, do tipo de vida que eles conseguem perseguir. A economia feminista defende que o bem-estar deve estar inserido em uma metodologia mais abrangente chamada provisão social, que considera a sobrevivência humana além de variáveis meramente materiais. A Abordagem das Capacitações tem aderência à economia feminista pois não restringe o bem-estar a questões financeiras, reconhece a diversidade humana e endossa os cinco critérios da abordagem de provisão social
\end{abstract}

PALAVRAS-CHAVE: Bem-estar, Teoria Econômica Neoclássica, Abordagem das Capacitações, Economia Feminista.

\begin{abstract}
Through a literature review, this paper aims to address the economic debate about the concept of well-being by providing parallels between the understanding of well-being from Amartya Sen's Capabilities Approach with that of feminist economics, as well as contrasting them with the understanding of neoclassical economic theory. According to the assumptions of the latter, well-being is seen as the satisfaction of preferences and evaluated according to the Pareto efficiency criterion. In opposition to this perspective, the Capabilities Approach conceptualizes well-being as a question of what subjects are capable of being and doing and, consequently, of the type of life they are able to pursue. The feminist economics argues that well-being must be inserted in a more comprehensive methodology called social provision, which considers human survival beyond merely material variables. The Capabilities Approach adheres to the feminist economics, as it does not restrict well-being to financial issues, it recognizes human diversity and endorses the five criteria of the social provision approach.
\end{abstract}

KEYWORDS: Well-being, Neoclassical Economic Theory, Capabilities Approach, Feminist Economics.

Classificação JEL: D60, I31, B54.

Recebido em: 07-10-2021. Aceito em: 05-01-2022. 


\section{INTRODUÇÃO}

A violência contra as mulheres é uma violação dos direitos humanos, talvez a mais vergonhosa de todas (ANNAN, 1999 apud GARCIA-MORENO; WATTS, 2011, p. 2), que se configura como um empecilho, dentre muitos outros, que as impedem de participarem plenamente da sociedade, gera consequências negativas para o bem-estar delas e de toda a sociedade. Ao trazer essa discussão para o âmbito da economia, é importante pensar em como essa disciplina trata o bem-estar social. Há diferentes teorias econômicas e, portanto, diferentes propostas concernentes à essa temática como é o caso da teoria econômica neoclássica, da Abordagem das Capacitações e da economia feminista.

De forma geral, a teoria econômica neoclássica deriva seu conceito de bem-estar do princípio de eficiência de Pareto que, em uma inspeção mais cuidadosa, é modelado segundo o conceito do homo economicus. Esse conceito evoluiu no pensamento econômico incorporando contribuições de diferentes pensadores da economia. O homo economicus se tornou proxy para o delineamento de um sujeito auto interessado, racional e maximizador individual de utilidade, que faz escolhas ótimas em um contexto de escassez e que possui preferências completas e estáveis. Dado a previsibilidade das decisões desse sujeito, a formulação de equações elegantes se torna viável (MARÇAL, 2017).

O princípio de eficiência de Pareto formula que um estado social só será alcançado se for impossível aumentar a utilidade de uma pessoa sem reduzir a utilidade de outra, e uma vez alcançado esse equilíbrio, não haverá incentivos a mudanças. $O$ tratamento do bem-estar dado pela teoria econômica neoclássica tem, de um lado, a otimalidade de Pareto como o único critério de julgamento e, de outro, o comportamento auto interessado como a única base de escolha econômica (SEN, 1999). Críticas à essa concepção estreita de bem-estar podem ser encontradas no pensamento de Amartya Sen que desenvolve, juntamente com Martha Nussbaum, a Abordagem das Capacitações (AC) bem como nas propostas da economia feminista, principalmente na sua crítica ao homo economicus e na defesa do provisionamento social como uma nova metodologia para a economia.

Há uma preocupação cada vez mais imperiosa na economia de que as estruturas de pensamento atualmente dominantes não sejam mais adequadas para abordar e analisar totalmente os complexos problemas de hoje, tal como o do bem-estar. No relatório da Commission on the Measurement of Economic Performance and Social Progress de 2009 
encabeçado por Joseph E. Stiglitz, Amartya Sen e Jean-Paul Fitoussi, cujo objetivo principal era identificar os limites do Produto Interno Bruto (PIB) como um indicador do desempenho econômico e do progresso social e avaliar ferramentas alternativas de medição, é dedicado espaço para argumentar alguns problemas da abordagem tradicional de medição do bemestar humano, que foca apenas na renda (STIGLITZ; SEN; FITOUSSI, 2009, POUW; MCGREGOR, 2014).

Em primeiro lugar, muitos recursos não são igualmente acessíveis a todos os indivíduos, o que torna problemático comparar a renda real entre as pessoas. Em segundo lugar, muitas das variáveis atreladas ao bem-estar humano não são recursos monetários, e sim, outros aspectos da vida das pessoas, como saúde, relações sociais, qualidade de trabalho, autoestima e lazer. E, em terceiro lugar, os recursos são transformados em bemestar de maneiras diversas entre as pessoas, ou seja, mesmo pessoas que possuem menos recursos econômicos podem estar em melhores níveis de bem-estar do que pessoas que comandam mais recursos econômicos se as primeiras têm, por exemplo, maior capacidade de realização em domínios valiosos da vida (STIGLITZ; SEN; FITOUSSI, 2009).

Para superar esses problemas é preciso pensar em formas alternativas de medir o bem-estar humano e adotar outros critérios metodológicos. Grande parte desses critérios vão de encontro com a $\mathrm{AC}$ e com a economia feminista. A começar com a ênfase nas pessoas, no que elas valorizam como importante para sua vida cotidiana e no ambiente em que se desenvolvem. Comunidades e instituições são avaliadas conforme os benefícios e/ou malefícios que trazem as pessoas que delas participam. Entender os sujeitos como os elementos fundamentais da análise também implica focar nos fins de várias atividades humanas, ao invés dos meios para realizá-las, tal como as abordagens baseadas em recursos priorizam (STIGLITZ; SEN; FITOUSSI, 2009; SEN, 2000; ROBEYNS, 2003).

Outro ponto é o reconhecimento das diversidades e desigualdades nas condições humanas: o bem-estar social depende tanto do nível agregado dos vários aspectos que se entrelaçam para construir a vida das pessoas quanto de como esses aspectos são distribuídos na sociedade (STIGLITZ; SEN; FITOUSSI, 2009). Ao considerar a diversidade humana, abre-se um diálogo direto com a pesquisa em economia feminista, uma vez que incluir a diversidade humana nas análises de bem-estar é importante para as análises de desigualdade de gênero (SEN, 2000; ROBEYNS, 2003). A necessidade de uma mudança na forma de avaliar o bem-estar passa por considerações como essas, mas essa alteração só será plena se houver uma construção de uma concepção diferente do ser humano que 
seja ontologicamente diferente da noção de homo economicus (POUW; MCGREGOR, 2014).

Com essas indagações em mente, a questão discutida é: como a AC e a economia feminista entendem o conceito de bem-estar social? Há complementaridade entre essas duas percepções? O objetivo é traçar, por meio de uma revisão de literatura, paralelos entre o entendimento de bem-estar proveniente da AC de Amartya Sen com o da economia feminista e contrapô-los com o entendimento da teoria econômica neoclássica.

O artigo apresenta o estudo teórico do conceito de bem-estar social seguindo, inicialmente, a estrutura de pensamento da teoria econômica neoclássica (seção 2). Após a explanação dessa abordagem, é discutida a proposta da AC de Sen $(1999,2001,2010)$ (seção 3), seguida da proposta da economia feminista e sua possível complementaridade com a AC (seção 5). A última seção (seção 5) é reservada as considerações finais.

\section{BEM-ESTAR A PARTIR DA TEORIA ECONÔMICA NEOCLÁSSICA}

A teoria econômica neoclássica debatida neste artigo pode ser definida como aquela fundada a partir da década de 1870 e compreende múltiplas abordagens desenvolvidas nos anos posteriores (DEQUECH, 2008) ${ }^{1}$. Agenjo-Calderón e Gálvez-Muñoz (2019) entendem que esta teoria detém uma grande influência na academia, seja no ensino ou na pesquisa, no debate político, e até mesmo sobre o senso comum das pessoas, legitimando aquilo que seria considerado como boa economia.

Conforme Beltrame e Mattos (2017), entre as décadas de 1930 e 1940, houve uma transição no campo da economia do bem-estar social: a chamada "Nova" Escola do BemEstar Social substituiu a "Velha" ou "Tradicional” Escola. Encabeçada por Arthur Cecil Pigou (1877 - 1959), a "Velha" Economia do Bem-Estar fundamentava sua visão a partir da ética benthamista e utilitarista de bem-estar que defende que, por intermédio da forma instrumental de medir a utilidade (contagem de utilidade), é possível formular políticas e leis que

1 Dequech (2008) caracteriza a teoria econômica neoclássica pela combinação das seguintes características: a) ênfase na racionalidade e no uso da maximização da utilidade como o critério de racionalidade, b) ênfase no equilíbrio ou nos equilíbrios, e c) negligência de fortes tipos de incerteza e, particularmente, de incerteza fundamental. Essa teoria entende que a sociedade alcançará o equilíbrio econômico quando os indivíduos possam buscar de forma auto interessada seu máximo benefício por meio da troca e da competição nos mercados (AGENJO-CALDERÓN; GÁLVEZ-MUÑOZ, 2019; DEQUECH, 2008). 
maximizem a felicidade de cada indivíduo privilegiando, entretanto, a felicidade geral. Esse cálculo seria condensado em um único índice factível de receber um valor numérico ou monetário, para ser passível de regulação por lei - uma função utilidade (BENTHAM, 2000; DIAS, 2012; BELTRAME; MATTOS, 2017). Esse seria o princípio da utilidade de Bentham que assumiu o hedonismo egoísta (a maximização da própria felicidade) como o princípio ético para o indivíduo, mas o hedonismo universal (a maximização da felicidade geral) para a legislação (NAKAI, 2012).

Bentham construiu sua ética utilitária como contra-ataque britânico no campo de batalha ideológica entre a substituição da tradição e do direito divino pelo lluminismo no século XVIII como base da legitimidade social por uma ética baseada no indivíduo, o que fez surgir os gêmeos inimigos: a liberdade igual, alcançada pelas revoluções americana e francesa, e a soma de felicidade (KOLM, 2000). Bentham considerava que os direitos naturais não passam de "idiotices cabais" e que os "direitos inatos e imprescritíveis [são] uma tolice retórica, besteiras com muletas"; seria como "berrar no papel" (SEN, 2017, p. 422). Bentham entende que é evidente que todos são "dotados pelo Criador de certos direitos inalienáveis", como exigia a declaração de independência americana, e que "os homens nascem e permanecem livres e iguais em direitos", como reivindica a declaração francesa de 1789. Em seus pronunciamentos morais baseados no utilitarismo, Anarchical Fallacies escrito em 1791-2, Bentham não tardou em propor o abandono completo das alegações dessas duas declarações (SEN, 2017, p. 422).

O raciocínio ético utilitário como o de Bentham insiste que as utilidades das pessoas envolvidas devem ser consideradas ao decidir sobre o que precisa ser feito, ao passo que a abordagem dos direitos humanos exige que as liberdades que são incorporadas na forma de direitos humanos devem receber reconhecimento normativo. À medida que Bentham escrevia sobre sua rejeição aos "direitos humanos", ficava alheio ao alcance e escopo das interpretações éticas dos direitos que estavam sendo explorados em obras como Rights of Man, de Thomas Paine (1791) e em A Vindication of the Rights of Woman: with Strictures on Political and Moral Subjects, de Mary Wollstonecraft (1792).

Essa visão lançou as bases para um entendimento utilitário da escolha segundo uma compreensão subjetivista do indivíduo. William Jevons (1835 - 1882), Carl Menger (1840 1921) e Léon Walras (1934 -1910) avançaram na concepção benthamista e utilitarista de bem-estar e foram os responsáveis por lançar as bases da Escola Neoclássica como teoria econômica no final do século XIX (FERNANDEZ, 2008; TORRES, 2015). Jevons, um dos primeiros a usar mais prolificamente a matemática nas questões econômicas, ambicionava 
tratar a utilidade como um item, paralelamente, subjetivo e mensurável; o prazer, uma questão subjetiva do indivíduo, poderia ser quantificável na medida em que a utilidade fosse entendida como uma função matemática que conduz o indivíduo. Jevons defendia que se é impossível comparar interpessoalmente os sentimentos, é possível, ao menos, estimar os seus efeitos quantitativos; uma referência a utilidade marginal (MARIN; QUINTANA, 2006). Também argumentava que a única forma de ação humana que merece atenção da economia é o comportamento maximizador racional. Baseado na noção de um consumidor calculista que busca prazer, Jevons "levou o homem econômico para o laboratório de matemática para caracterizar seu comportamento com um novo nível de exatidão e para investigar as leis de seu comportamento" (MORGAN, 2006, p. 12 apud GRECCO, 2018, p. 116).

Menger, outro expoente do marginalismo e que privilegiava a argumentação retórica e o uso de diagramas numéricos simples em seus trabalhos, concebeu o homem econômico como um economizador e não um maximizador (TORRES, 2015). As avaliações subjetivas desse homem econômico estariam sujeitas à satisfação de diferentes necessidades e desejos, que seriam regidos por meio de escolhas racionais (GRECCO, 2018). Walras, ao contrário de Menger, defendia que a introdução da matemática na economia torna a ciência finalmente exata e mais parecida com a física mecânica. Afinal, com um corpo teórico matemático passível de ser testado e avaliado, a distância da economia de considerações metafísicas e éticas se faria cada vez maior (TORRES, 2015; MARIN; QUINTANA, 2006).

O conceito de homo economicus formalizado pelos marginalistas nas últimas décadas do século XIX deu ensejo à axiomatização matemática, um método dedutivo em que uma verdade lógica é exclusivamente derivada de premissas consideradas necessárias. $\mathrm{Na}$ economia, utiliza-se esse método para explicar inclusive as preferências do comportamento humano, numa tentativa de simplificá-las para o uso matemático (TORRES, 2015). Dessa formulação em diante, a noção de homo economicus segue com fundamental importância para a completude da teoria econômica neoclássica. A depender da abordagem e do método de cada pensador, o homo economicus figura como um sujeito individual, racional, autocentrado e egoísta, sendo o desejo pelo lucro substancial para sua existência (GRECCO, 2018).

No final da década de 1930, dúvidas a respeito da cientificidade da economia surgiram por conta do economista britânico Lionel Robbins (1898-1984), que defendeu a impossibilidade de comparações interpessoais de utilidade, haja vista que essas comparações não envolvem coisas observáveis e, portanto, não dizem respeito à ciência nem à economia (HANDS, 2001, p. 36 apud BELTRAME; MATTOS, 2017). Segundo Baker 
(1995), para Robbins, não haveria uma forma cientificamente aceita de testar a magnitude da satisfação de uma pessoa em comparação com a de outra, já que propostas baseadas em comparações interpessoais de utilidade não poderiam ser verificadas por observação ou introspecção. Robbins, porém, não rejeitou a possibilidade de fazer comparações interpessoais de utilidade, nem condenou os economistas que as faziam, mas afirmou que tal exercício não pode reivindicar qualquer validade objetiva (SUZUMURA, 2002).

Esse posicionamento se mostrou influente a ponto de outros economistas passarem a defendê-lo. Suprimida as comparações interpessoais de utilidade e, em consequência, as políticas e/ou leis distributivas e de bem-estar que delas se derivavam e a orientação hedonística da teoria da utilidade cardinal, o princípio que regeria o bem-estar social seria o critério da eficiência de Pareto elaborada por Vilfredo Pareto (1848 - 1923) (BELTRAME; MATTOS, 2017, SUZUMURA, 2002). O critério de Pareto expressa um fenômeno puramente de eficiência econômica, que trata a maneira ótima de usar os recursos e que descreve as preferências dos agentes econômicos por meio de utilidades ordinais. A caracterização e implementação da alocação eficiente de recursos em termos de Pareto tornou-se o exercício central na "nova" fase da economia do bem-estar, representada por John Hicks (1904 - 1989) (SUZUMURA, 2002; SEN, 1999; STIGLITZ, 1999).

Para Baker (1995), o desenvolvimento da otimalidade de Pareto como um critério científico de avaliação do bem-estar econômico foi uma resposta às tensões metodológicas entre a natureza política da economia e as aspirações científicas dos economistas. A eficiência foi a ponte que conectou a economia a um sistema de pensamento transcendente, a-histórico e apolítico. A força ética do conceito de eficiência baseada nos princípios de autonomia, consentimento e preferências, assim como a possibilidade de seu uso em entender como as preferências individuais são expressas em mercados competitivos, tornam a otimização de Pareto um critério convencional para julgar o bem-estar econômico.

A otimização de Pareto se tornou central para a economia como consequência do desenvolvimento do Teorema Fundamental da Economia do Bem-Estar que "relaciona os resultados do equilíbrio de mercado em concorrência perfeita com a otimalidade de Pareto" e se apresenta de duas formas: 1) em certas condições, cada equilíbrio perfeitamente competitivo é um ótimo de Pareto e 2) cada estado social ótimo de Pareto é também um equilíbrio perfeitamente competitivo para alguma distribuição inicial de renda ou dotações (SEN, 1999, p. 50). Esse teorema atrai os economistas, porque fornece uma visão profunda do funcionamento do mecanismo de preços; explica a natureza mutuamente vantajosa do comércio, da produção e do consumo guiados pelo interesse próprio, e permite expressar 
todas as condições de consumo e oferta de trabalho em termos de funções de preferência individual (BAKER, 1995; SEN, 1999).

Francis Ysidro Edgeworth (1845-1926) e John Hicks (1904-1989) desenvolveram o insight de Pareto e construíram uma teoria completa do comportamento do consumidor com base na utilidade ordinal (TORRES, 2015; BELTRAME; MATTOS, 2017). Duas abordagens alternativas estenderam esse critério. A primeira, de Nicholas Kaldor (1908-1986), John Hicks (1904-1989), Tibor de Scitovsky (1910-2002) e Paul Anthony Samuelson (1915-2009) com os critérios de compensação: introdução de pagamentos compensatórios de acordo com os benefícios e prejuízos para as pessoas de uma mudança na política econômica. E a segunda, mais influente, a função de bem-estar social de Bergson-Samuelson que partia das decisões individuais e não mais de intensidades cardinais relativas a estados mentais individuais. No fim das contas, essa função promoveu a separação do que é apropriado à ética e à economia do bem-estar (SUZUMURA, 2002).

Inspirado por toda essa discussão e em especial pela função de bem-estar social de Bergson-Samuelson, Kenneth Arrow (1921-2017) contribuiu no campo da economia do bemestar, apesar de muitos acreditarem que suas contribuições são mais apropriadas para a área da Escolha Social. Arrow (apud BELTRAME; MATTOS, 2017), em tônica com os princípios da "nova" economia do bem-estar - welfarismo, ordinalismo, impossibilidade de comparações interpessoais de utilidade e paretianismo - e com o pensamento de Bergson e Samuelson, aprovava o uso de funções de bem-estar social para converter decisões individuais em decisões coletivas e defendia a ideia de que, por meio da observação das escolhas individuais, as preferências poderiam ser acessadas (BELTRAME; MATTOS, 2017).

Arrow defende que a origem do valor social repousa nas próprias escolhas sociais no sentido de que corresponde a regras ou procedimentos de escolha social, responsáveis por garantir a vinculação democrática entre a escolha social e os valores individuais (ARROW, 1963, p. 106 apud BELTRAME; MATTOS, 2017; SUZUMURA, 2002). A função de bem-estar que Arrow criou leva em conta a sua noção de valor social e é derivada de quatro axiomas que garantiriam que a função atenderia os critérios de eficiência e de democracia. Conforme o primeiro axioma, qualquer indivíduo é livre para construir a ordem de preferência que desejar, representando suas avaliações da bondade dos estados sociais. A função de bemestar social de Arrow deve ser robusta o suficiente para ser capaz de agregar essas ordens de preferências individuais em uma ordem de preferência social. O segundo axioma exige a expressão da unanimidade no sentido de que a função de bem-estar social de Arrow deva 
refletir fielmente a preferência unânime expressa por todos os indivíduos sobre um par de estados sociais. Isso torna o processo de agregação de preferências minimamente democrático. O terceiro axioma exige que a função de bem-estar social de Arrow deve ser informacionalmente eficiente; ao decidir se um estado social é melhor, pior ou indiferente a outro estado social, é mandatório saber como os indivíduos classificam esses dois estados sociais - exige independência de alternativas irrelevantes. Por fim, o quarto axioma demanda a não existência de ditador na sociedade; ninguém pode ser capaz de decidir pelos outros (BELTRAME; MATTOS, 2017; SUZUMURA, 2002).

A partir desses axiomas, Arrow chega ao resultado da Impossibilidade. Se essas quatro hipóteses são válidas, não há sistema (de votação) capaz de implementar alocações eficientes no sentido de Pareto. Ao verificar a impossibilidade lógica de uma função de bemestar social que atenda, simultaneamente, essas quatro hipóteses, o comprometimento com a democracia no processo de escolha social se esvai (BELTRAME; MATTOS, 2017). Como é ressaltado por Suzumura (2002), uma vez que Teorema da Impossibilidade de Arrow respeita a tradição anterior - nova economia do bem-estar e o pensamento de BergsonSamuelson - esse teorema tornou-se relevante e um indicativo da necessidade de um sistemático escrutínio na busca de soluções para a contradição lógica identificada pelo próprio teorema.

Em suma, a "nova" economia do bem-estar passou a ser fundamentada nos seguintes elementos normativos: a) welfarismo, que requer que a função de bem-estar social seja baseada nos níveis de utilidade individual: o julgamento da bondade relativa de quaisquer dois estados de coisas alternativas seja tomado como uma função crescente das respectivas coleções de utilidades individuais nesses mesmos estados; b) ordinalismo: apenas as propriedades ordinais de ranqueamento das funções de utilidade individuais devem ser usadas em julgamentos de bem-estar social; c) impossibilidade de comparação interpessoal de utilidade, ou seja, "[t]he social welfare ranking must be independent of the way the utilities of different individuals compare with each other" (SEN, 1979b, p. 538); e d) A regra de Pareto que afirma que "[i]f everyone has at least as much utility in $x$ as in $y$, and if someone has more utility in $x$ than in $y$, then $x$ is socially better than $y^{\prime \prime}$ (SEN, 1979b, p. 538; SEN, 1979a, HAUSMAN; MCPHERSON, 2006).

\section{BEM-ESTAR A PARTIR DA ABORDAGEM DAS CAPACITAÇÕES}


Dentre as limitações da abordagem utilitarista de bem-estar apontadas por Sen (1999, 2000), duas são especialmente importantes para a complementaridade entre AC e a economia feminista: a impossibilidade de comparações interpessoais de utilidade e o descaso com os direitos humanos. A primeira é justificada pela teoria neoclássica pelo fato de que como as pessoas são diferentes, elas valorizam o mesmo bem de forma diferente e possuem necessidades individuais distintas. A abordagem utilitarista ignora a importância da reivindicação de direitos, da liberdade e outras considerações desvinculadas da utilidade e, quando o aborda, faz somente na proporção que beneficia a utilidade (COELHO, 2011; SEN, 1999, 2000; BELTRAME; MATTOS, 2017). Para Sandel (2015), essa é justamente uma das objeções da filosofia de Bentham: a impossibilidade de respeitar os direitos individuais; indivíduos têm importância apenas enquanto suas preferências forem consideradas em conjunto com os demais.

Como as preferências individuais são consideradas pela teoria neoclássica sem a devida atenção a fatores que vão além da satisfação de utilidade como, por exemplo, tradições e crenças, despreza-se os juízos que a pessoa forma sobre a sua utilidade a partir de costumes, social e culturalmente construídos. O resultado seria uma acomodação da pessoa aos estados indesejáveis de sua vida, fazendo com que ela se resignasse com preferências 'baratas', enquanto outras tenham preferências 'caras'. Ao apoiar-se na utilidade e nas preferências dos indivíduos, a abordagem utilitarista do bem-estar fecharia os olhos as assimetrias de informação e de condição existentes entre as pessoas (COELHO, 2011; SEN, 1999).

Sen (1977) também critica a interpretação utilitarista da racionalidade humana e do comportamento humano: pontua sua limitação em compatibilizar, exclusivamente, racionalidade e interesse próprio. Sen (1977) argumenta que as escolhas reais podem não refletir a lógica maximizadora da teoria da escolha racional, uma vez que a "choice may reflect a compromise among a variety of considerations of which personal welfare may be just one" (SEN, 1977, p. 324). Um insight inicial de Sen foi que a escolha individual e o bem-estar nem sempre precisam ser combinados, como havia sido geralmente assumido na economia neoclássica ao caracterizar os indivíduos como agentes maximizadores de utilidade (DAVIS, 2003).

É imprescindível considerar que existe uma parcela do comportamento humano que não faz sentido se pensarmos na racionalidade como maximização do interesse próprio. Ação coletiva e sacrifício religioso são alguns desses exemplos. Os indivíduos buscam uma variedade de objetivos na vida, além daqueles que atendem imediatamente a seus próprios 
interesses e ao seu próprio bem-estar. Eles ponderam situações envolvendo seus comprometimentos, suas simpatias pelos outros e seu desejo de dirigir livremente suas próprias vidas, embora nem sempre isso aconteça (DAVIS, 2003).

Sen (1999, 2001, 2010), junto com a filósofa Martha Nussbaum (1992, 1999, 2000 , 2003, 2011), desenvolve a AC que busca a superação da tese de contar utilidades ou ordenar preferências por meio de funcionamentos e capacitações humanas. As pessoas podem "funcionar", isto é, fazer ou ser alguma coisa, de várias maneiras. Muitas dessas maneiras são triviais (triviais para alguns, nem tanto para outros), mas muitas outras representam funções básicas essenciais para o florescimento humano ou para a construção de uma agência valiosa ou de uma valiosa e engajadora ação humana. Os funcionamentos correspondem a "estados" e "ações", constituindo o bem-estar de uma pessoa. Capacidade de ler, escrever; estar bem nutrido, livre de doenças e fisicamente apto; ser instruído, feliz e ter respeito próprio, são alguns dos exemplos. Similarmente, uma pessoa ainda pode se preocupar com outros estados de ser e fazer como, por exemplo, querer ser extrovertida, almejar criar os filhos e jogar futebol (SEN, 2001; RICHARD, 2013; ANDERSON, 1999).

Considere agora todos os conjuntos de funcionamentos que uma pessoa é realmente livre para escolher. Tais conjuntos formam as capacitações dessa pessoa. As capacitações refletem o poder da pessoa de escolher um tipo de vida e conseguir levar a cabo essa escolha. As capacitações são únicas para cada indivíduo; dependem de características pessoais, combinações sociais, contexto histórico e recursos disponíveis, sejam pessoais, materiais elou sociais. Não medem funcionamentos realmente adquiridos, mas sim a liberdade de uma pessoa para adquirir os funcionamentos valorizados. A liberdade de uma pessoa está condicionada a uma série de oportunidades efetivamente acessíveis para levar sua vida da forma que ela valorize mais; quanto maior essa gama de oportunidades, maior a liberdade (SEN, 2001; RICHARD, 2013; ANDERSON, 1999).

Como Sen (2001) afirma, a relação entre capacitações e bem-estar se encontra em: (1) enquanto os funcionamentos realizados fazem parte do próprio bem-estar, as capacitações para realizar tais funcionamentos se enquadram na liberdade da pessoa ou nas oportunidades para se ter tal bem-estar e (2) essa relação está intimamente ligada em "fazer o próprio bem-estar realizado depender da capacitação para realizar funcionamentos" (SEN, 2001, p. 90-91).

O reconhecimento da diversidade de objetivos individuais motivou Sen $(1999,2000)$ a fazer duas distinções com relação à natureza das motivações individuais. Como os objetivos de uma pessoa podem envolver questões distintas das do seu bem-estar, é indispensável 
distinguir entre a busca pelo bem-estar individual e a busca pelas metas gerais da agência. Agência é entendida como ação e o ato de provocar mudanças: uma pessoa cujas realizações podem ser julgadas em termos de seus próprios valores e objetivos. A agência invoca a capacidade de superar barreiras, questionar ou confrontar situações de opressão e privação, assim como ter a capacidade de ter influência e ser ouvido na sociedade, seja como indivíduo, seja em conjunto com outros. A segunda distinção se liga ao fato de que, uma vez que ser livre para perseguir uma variedade de objetivos é valioso para as pessoas, também é importante distinguir entre a liberdade de alcançar os objetivos e a liberdade de simplesmente persegui-los. Essas duas distinções resultam em quatro conceitos relativamente distintos, mas às vezes sobrepostos: 1) realização do bem-estar, 2) realização da agência, 3) liberdade de bem-estar, 4) liberdade da agência (SEN, 1999, 2000; DAVIS, 2003; HANMER; KLUGMAN, 2016).

A realização do bem-estar representa a preocupação da abordagem utilitarista no que tange ao interesse dos indivíduos em satisfazer suas próprias preferências. A realização de agência refere-se à capacidade das pessoas em atingir metas que não envolvam, necessariamente, seu próprio bem-estar. Enquanto a liberdade de bem-estar se relaciona com a preocupação das pessoas que têm a liberdade de buscar seu próprio bem-estar, a liberdade de agência é associada à liberdade das pessoas em perseguir todos os seus objetivos, sejam eles bem-sucedidos ou não. Essa pluralidade informacional contrasta com a abordagem utilitarista que reduz esse processo em um duplo movimento ao considerar, por um lado, que a liberdade é valiosa apenas instrumentalmente de forma a contar apenas a realização e a supor, por outro lado, que a condição de agente se orienta exclusivamente por meio de interesses individuais. Esse duplo processo transforma toda essa pluralidade informacional numa massa homogênea, utilidade, e limita a articulação com a avaliação ética (SEN, 1999; DAVIS, 2003).

A AC também pode ser desenvolvida de diferentes maneiras, dependendo de como as capacitações básicas são identificadas (RICHARD, 2013). Nussbaum (1992, 1999, 2000, 2003, 2011), a título de exemplo, explora a AC segundo uma explicação objetiva do bemestar ou do florescimento humano, a ponto de identificar todos os funcionamentos necessários para tanto. O ideal é que cada pessoa seja "nutrida" de forma a se engajar em cada um desses funcionamentos em um nível satisfatório ou bom o suficiente para promover o bem-estar ou uma vida social minimamente aceitável em diferentes áreas da vida humana. 
Nussbaum (2000, p. 5) concebe uma lista de dez capacitações centrais e universais que pode ser traduzida em listas mais detalhadas e específicas para se adequar ao contexto².

A abordagem de Sen $(2000,2001)$ não envolve listas de capacitações específicas: no seu entendimento, as capacitações dependerão tanto do contexto social, econômico, cultural e histórico em que a pessoa está inserida como de aspectos pessoais. Dessa forma, o conjunto capacitário pode variar de pessoa para pessoa e cada aplicação da abordagem exigirá sua própria lista (ROBEYNS, 2003).

A AC se insere no debate da distinção entre meios e fins humanos. Sen (1999) destaca que Aristóteles via a riqueza em si como um meio para atingir alguma coisa e não como o bem final que uma pessoa almeja. Em vez de focar nos recursos que uma pessoa comanda, recursos estes valorizados por constituírem um meio para alcançar o que as pessoas têm razão em valorizar na vida, o foco da avaliação da AC está nos fins, na liberdade de realizar os fazeres e seres, ou os funcionamentos, que as pessoas entendem como importantes para sua vida, o que se reflete em suas capacitações (ROBEYNS, 2021).

A importância dos fins na AC se encontra na pressuposição de que há diferenças entre os indivíduos que afetam na conversão de recursos em funcionamentos, diferenças originadas em diferentes contextos sociais e ambientais, normas relacionadas a fatores de identidade, como gênero e raça, bem como diferenças e deficiências físicas e mentais. As pessoas diferem em sua capacidade de converter meios em oportunidades valiosas, refletidas por seu conjunto capacitário, ou resultados (funcionamentos alcançados). Um segundo motivo da exigência da $A C$ de ter como ponto de partida os fins é que existem alguns fins de importância vital que não dependem, necessariamente, dos meios materiais e, por isso, não seriam captados se a análise apenas considerasse os meios. É o caso, por exemplo, de respeito próprio; apoio da família, no local de trabalho ou na comunidade; boa saúde mental e amizade. Ou seja, fins que não possuem meios análogos que possam ser usados como substitutos mensuráveis (ROBEYNS, 2021).

A AC possui um compromisso sério com o pluralismo, que é exercido por dois elementos: análise multidimensional e pluralismo de valores. Na análise multidimensional, é pertinente ter em mente que o exame do bem-estar e da liberdade, que formam as noçõeschave na $\mathrm{AC}$, e os conceitos derivados dessas noções como pobreza, riqueza, desigualdade e justiça distributiva, sempre implicará em uma pluralidade de dimensões. No pluralismo de

${ }^{2}$ A lista é a seguinte: 1. life; 2. bodily health; 3. bodily integrity; 4. senses, imagination, and thought; 5. emotions; 6. practical reason; 7. affiliation; 8. other species; 9. play; e 10. control over one's environment (NUSSBAUM, 2000, p. 5). 
valores, a AC alega que não há precedência de alguns valores sobre outros - o bem-estar e a liberdade não são as únicas coisas que importam. Podem existir outros valores e princípios morais tão importantes quanto, e que, devido às suas características, seriam melhores captados fora da estrutura de capacitações. Valores relacionados a processos como transparência e ausência de corrupção são muito importantes e talvez a linguagem das capacitações não os analisariam da melhor maneira (ROBEYNS, 2021).

Outra importante questão que perpassa a AC é a relevância dos direitos humanos. A AC e a abordagem dos direitos humanos compartilham a preocupação na dignidade e na liberdade do indivíduo. A AC, por um lado, destaca a importância crítica das liberdades e oportunidades substantivas de indivíduos e grupos; a abordagem dos direitos humanos, por outro lado, destaca a importância de valores como liberdade, dignidade e respeito, igualdade e não discriminação, participação e autonomia, e os arranjos necessários para protegê-los e promovê-los. São duas abordagens que entram em contraposição às abordagens de política econômica que enfatizam a expansão do Produto Interno Bruto (PIB) ou de outras variáveis essenciais como seus principais objetivos na melhora da qualidade de vida e bem-estar (VIZARD; FUKUDA-PARR; ELSON, 2011).

O conceito de capacitação fornece um ponto de partida para defender a validade de uma ampla classe de direitos humanos, como é o caso dos direitos econômicos e sociais. Um exemplo é avaliar o padrão de vida adequado, que considera questões como alimentação e abrigo adequados, e o direito humano à saúde. É uma estrutura conveniente para tratar os direitos civis e políticos, como liberdade de tortura, tratamento cruel e desumano, e o direito a um julgamento justo. A AC também é capaz de capturar as liberdades e oportunidades que estão ao alcance de uma pessoa, isto é, o seu conjunto de capacitações, bem como as variáveis subjacentes que explicam esse conjunto tais como variáveis contextuais, fatores de conversão e o sistema de direitos. Em suma, a AC complementa a análise tradicional dos direitos humanos ao fornecer uma estrutura aplicada que permite avaliar e apontar fatores passíveis de influência na realização prática dos direitos humanos (VIZARD; FUKUDAPARR; ELSON, 2011).

\section{BEM-ESTAR A PARTIR DA ECONOMIA FEMINISTA E SUA COMPLEMENTARIEDADE COM A ABORDAGEM DAS CAPACITAÇÕES}

A economia feminista surge na década de 1990 quando a conferência anual da American Economic Association incluiu, pela primeira vez, um painel relacionado às 
perspectivas feministas na economia. Sendo um dos mais recentes programas de pesquisa em economia, a economia feminista concilia-se com diferentes bases teóricas - escola neoclássica, institucionalista, pós-keynesiana, etc. - e inclinações políticas do movimento feminista - liberal, radical, marxista. Por não ser um corpo teórico homogêneo, a economia feminista identifica o gênero como categoria analítica comum, transformando-o em um ponto de tangência na miríade de vozes que falam em seu benefício (FERNANDEZ, 2008, 2018).

Desde sua origem, a economia feminista vem repensando e desafiando questões econômicas centrais como valor, poder, direitos, bem-estar, eficiência, escassez, onipresença do egoísmo, independência das funções de utilidade e impossibilidade de comparações interpessoais de utilidade. Ao questionar, por exemplo, a impossibilidade de comparações interpessoais de utilidade, a economia feminista se alinha à suposição básica do feminismo de que as mulheres são oprimidas e que essa opressão deve ser combatida. Apesar dos protestos, os economistas fazem comparações interpessoais de utilidade que, em muito, prejudicam as mulheres (STROBER, 1994).

Segundo Nelson (1983), a definição de economia centrada na escolha, tal como defendida por Robbins, provoca uma cisão radical das decisões humanas entre restrições físicas e sociais, negligenciando essas últimas; enfatiza o bem-estar material em detrimento das influências não físicas na satisfação humana, e reforça a separação dos humanos em relação ao mundo. Nelson (1993) defende que a definição de economia deve repousar na provisão da vida humana, ou seja, nas mercadorias e processos necessários à manutenção da sobrevivência humana. A AC defende a relação entre as necessidades humanas e o mundo, o que já a conciliaria com o projeto de pesquisa da economia feminista.

Muitas das questões que a economia feminista busca responder entra em contato com o que Sen (1999) chamou de questões de ética em economia. Praticidade e eficiência, lados engenheiros da economia e os mais privilegiado pela tradição neoclássica, são tão importantes quanto moralidade e justiça, lado ético. A centralidade de conceitos como eficiência, escassez, competição e motivações hedonistas como egoísmo prejudicam os interesses das mulheres e torna mais difícil ponderar problemas como redistribuição de poder e bem-estar, além de tratar a motivação humana de forma limitada. A economia feminista desafia a economia tradicional a repensar suas prioridades e a levar a sério a preocupação com o bem-estar, qualidade de vida, cooperação e equidade (STROBER, 1994; BERIK; KONGAR, 2021).

Mas como essa crítica se alinha com a visão da economia feminista sobre o bemestar? Muito dessa reflexão passa pelo conceito de provisão social. Power (2004) usa esse 
termo para descrever uma metodologia emergente para a economia baseada em diferentes componentes: 1) incorporação das atividades de cuidado e não remuneradas como atividades econômicas fundamentais; 2) análise de processos econômicos, políticos e sociais, relações de poder e agência; 3) inclusão de objetivos e valores éticos como parte intrínseca da análise; 4) análise das diferenças por classe, raça-etnia e outros fatores, e 5) entender o bem-estar como medida do sucesso econômico.

Power (2004) ressalta que o conceito de provisão social é um conceito clássico, influenciado por estruturas conceituais derivadas de Marx e da economia política, de Veblen e da economia institucionalista e de Sen e da AC. É um conceito que considera a interdependência e a cooperação das pessoas e as suas habilidades de garantir e proteger seus meios diários e intergeracionais de subsistência. É sensível a uma análise histórica e social, e à agência dos sujeitos. Pelo conceito de provisão social, os indivíduos são trespassados por diferentes identidades socialmente atribuídas e, por meio de relações sociais de conflito e cooperação, essas identidades impactam os resultados econômicos obtidos (POWER, 2004; BERIK; KONGAR, 2021). Power (2004, p. 15) conclui que o conceito de provisão social "is a fruitful beginning for an economic analysis that has at its core a concern with human well-being, with the empowerment of subordinated groups" e, conforme Beneria (2003, p. 167-8 apud POWER, 2004, p. 15), representa "the fulfillment of human potential in all its dimensions - for each and everyone".

Uma vez que o bem-estar depende de diferentes considerações, entendê-lo por meio de capacitações é um passo fundamental para efetivar o conceito de provisão social. O nível de renda, central para a lógica utilitarista, se torna um dos meios para atingir as capacitações. Para a economia feminista, os rendimentos são gerados pelo trabalho assalariado, assim como pelas atividades de provisionamento, passíveis de ocorrerem em vários locais como em casa e no mercado de trabalho, e influenciadas por uma série de relações sociais. É possível dizer que as atividades assalariadas e as não remuneradas são interdependentes tanto no nível familiar quanto no comunitário. Nesse sentido, pensar em situações dentro e fora do mercado constitui uma complementaridade entre a AC e a economia feminista. Analisar o bem-estar apenas por meio de mecanismos de mercado como renda e emprego invisibiliza aspectos essenciais como as atividades domésticas e de cuidado, experiências de violência doméstica e disponibilidade de redes de apoio. Considerando que as mulheres passam mais tempo fora do mercado do que os homens, ignorar esses aspectos impacta diretamente em avaliações relacionadas ao gênero e ao bem-estar (ROBEYNS, 2003; POWER, 2004; BERIK; KONGAR, 2021). 
Pela visão da economia feminista, a avaliação adequada do bem-estar econômico requer atenção não apenas em relação a distribuições agregadas ou à renda, mas também aos direitos individuais e a heterogeneidade das necessidades humanas. A AC abre espaço para compreender o bem-estar por meio da interdependência humana e do levantamento de questões envolvendo gênero e desigualdades. É uma abordagem que enfatiza os processos e os resultados, e chama atenção para as dinâmicas culturais e sociais, além das materiais (POWER, 2004). Berik, Rodgers e Seguino (2009), favoráveis à AC, afirmam que o bemestar requer, no mínimo, três elementos: o provisionamento adequado conforme a interligação entre o trabalho remunerado e as atividades de cuidado não remuneradas; capacitações, ou seja, as formas de fazer e ser das pessoas, com base no provisionamento; e agência, a habilidade de participar na tomada de decisões de forma a moldar o mundo em que se vive.

É evidente o potencial da AC em tratar de preocupações e questões feministas. Saúde reprodutiva, direito de voto, poder político, violência doméstica, educação e status social das mulheres são alguns dos exemplos. A primeira vantagem da AC para a economia feminista é que os funcionamentos e as capacitações são propriedades das pessoas. Isso significa que é uma teoria eticamente individualista em que as unidades de julgamento normativo são pessoas, e não famílias ou comunidades. Cada pessoa é considerada nos julgamentos normativos. Mas, a AC não é ontologicamente individualista, ou seja, não pressupõe indivíduos atomísticos, muito menos que os funcionamentos e as capacitações sejam independentes de preocupações com os outros ou das ações de outros (ROBEYNS, 2003).

Robeyns (2021) argumenta que a coesão e sobreposição entre o conceito de provisão social e a AC advém não somente da compartilhada definição de bem-estar, mas também do fato de que a AC endossa todos os cinco critérios de provisão social, como explicado por Power (2004). Considerando o critério de que o bem-estar deve ser a medida do sucesso econômico, sabe-se que a AC foi desenvolvida com o objetivo de superar as métricas monetárias que se detêm em recursos como, por exemplo, o PIB per capita, renda produtividade econômica - característica de análises derivadas da teoria econômica neoclássica. A AC se afasta da unidimensionalidade dessas visões, que se baseiam nos meios para se chegar aos fins desejados, e foca diretamente nos fins, isto é, nas coisas que importam intrinsecamente e que garantem uma vida dignamente boa. Recursos monetários são importantes meios para garantir uma vida digna, porém muitas das variáveis atreladas ao bem-estar aludem a outros aspectos da vida das pessoas como, por exemplo, respeito próprio, relações sociais, apoio no local de trabalho ou na comunidade, boa saúde mental, 
amizade, autoestima e lazer. Impor preços a "recursos" como esses retira a complexidade desses aspectos, sem contar que o próprio processo de imputação seria obscuro (ROBEYNS, 2021; STIGLITZ; SEN; FITOUSSI, 2009).

Outra razão apontada por Robeyns (2021) que endossa o critério de bem-estar como medida de sucesso econômico é a diversidade humana que a AC adere. Sen $(2000,2001)$ adverte que entender o bem-estar como uma função apenas do vetor de rendas, em que uma distribuição igual desta renda deve maximizar o bem-estar social, é uma forma muito estreita de se analisar a diversidade individual. Considerar que todas as pessoas convertem certo nível de renda no mesmo nível de bem-estar é negar a presença das diversidades que podem fazer com que duas pessoas tenham oportunidades ou qualidade de vida completamente diferentes, mesmo quando compartilham exatamente a mesma cesta de bens. As pessoas precisam de diferentes quantidades e diferentes tipos de recursos para atingir os mesmos níveis de bem-estar, porque isso depende dos fatores de conversão que tornam viável a conversão de mercadorias e recursos em funcionamentos. Sem contar a importância dos contextos sociais, institucionais e ambientais que afetam os fatores de conversão e a capacitação diretamente correspondente (ROBEYNS, 2021; STIGLITZ; SEN; FITOUSSI, 2009).

A noção de bem-estar pelas capacitações é um útil recurso para a abordagem da provisão social e pode ser bem desenvolvida por esta, uma vez que se adere ao entendimento de Power (2004, p. 5) de que "[p]roperly evaluating economic well-being requires attention not only to aggregate or average distributions of income and wealth, but also to individual entitlements and what Amartya Sen has identified as the heterogeneity of human needs".

Em relação ao critério da abordagem da provisão social que advoga pela inclusão das atividades de cuidado e das não remuneradas no escopo de atividades econômicas fundamentais, atividades que devem ser "incorporated into the analysis from the beginning, not shoehorned in as an afterthought' (POWER, 2004, p. 4), Robeyns (2021) aponta dois motivos da complementaridade entre a AC e a provisão social. O primeiro motivo resvala na questão dos fins para uma vida valorosa: "care and unpaid labor can be conceptualized as things that matter to people directly, hence as being among the many ends of a worthwhile life" (ROBEYNS, 2021, p. 75). A promoção de atividades não remuneradas de cuidado, usualmente levadas a cabo pelas mulheres, produz bens e serviços complementares à produção mercantil, gera e zela por uma série de valores interpessoais de pertencimento e compartilhamento que são associados a responsabilidade, lealdade, generosidade e 
confiança. Esses valores impactam positivamente a manutenção do bem-estar daqueles em que o cuidado é direcionado. Entretanto, como o cuidado é uma atividade que desgasta física e emocionalmente, demanda tempo e energia, além de recursos materiais, para aquelas que desempenham essa atividade, pode haver uma redução de funcionamentos básicos (STAVEREN; GASPER 2002). Como alinhar o bem-estar de mulheres responsáveis por atividades de cuidado numa teoria que não permite comparações interpessoais de utilidade?

Para Robeyns (2021), as atividades de cuidado possuem um custo de oportunidade, já que questiona como o tempo despendido cuidando poderia ter sido gasto de outra forma e, dado a distribuição dessas atividades, surge a questão de justiça social e econômica. Ao passo que a real liberdade de cuidar pode ser vista como uma capacitação e valiosa por si mesma, o cuidar propriamente dito seria visto como um funcionamento. Essa distinção é relevante; o cuidado efetivamente prestado não tem valor se não houver uma liberdade correspondente, ou seja, se não houver a opção de não cuidar ou se o cuidador for forçado a cuidar. Robeyns (2021) conclui que as atividades de cuidado são tanto um recurso valioso para outras capacitações, porque influenciam positivamente o florescimento das pessoas em dimensões valiosas da vida como saúde mental e relações sociais estáveis, quanto uma capacitação em si no sentido de que algumas pessoas a valorizam por direito próprio.

No que tange ao critério da inclusão de objetivos e valores éticos como parte intrínseca da análise na abordagem da provisão social, "ethical judgments are a valid, inescapable, and in fact desirable part of an economic analysis" (POWER, 2004, p. 5), e a AC se engaja em projetos normativos e enfatiza que não é possível ter qualquer abordagem que trate da formulação de políticas que não seja normativa. Como determinar se uma política é melhor que outra sem o comprometimento com esses objetivos, "the ends that matter" (ROBEYNS, 2021, p. 76), e com valores centrais na avaliação? No caso da teoria neoclássica, a ênfase da satisfação de preferências é como um objetivo inquestionável, mas que traz certos prejuízos para a análise do bem-estar. Ao ignorar outras informações que não a satisfação de utilidade ou o ordenamento de preferências, despreza-se os juízos que a pessoa forma sobre a sua utilidade a partir de costumes, social e culturalmente formados. Como resultado das preferências adaptativas, pode existir uma acomodação da pessoa para com circunstâncias indesejáveis de sua vida, o que torna a abordagem utilitarista do bem-estar insensível às assimetrias de informação e de condição existentes entre as pessoas. Isso se torna particularmente relevante quando se trata das mulheres, já que as mulheres usualmente lidam com circunstâncias piores do que os homens e com normas sociais que as induzem a aceitá-las. Se as mulheres se adaptarem a essas circunstâncias adversas, uma 
métrica baseada em preferências pode se tornar alheia às injustiças e desigualdades de gênero (ROBEYNS, 2021; COELHO, 2011; SEN, 1999).

Outra característica compartilhada entre a AC e a abordagem da provisão social é a natureza interdisciplinar. Ambas as abordagens são multidisciplinares; exigem percepções, ferramentas e métodos que se originam de diferentes disciplinas nas ciências sociais e humanas. A teoria neoclássica é uma "highly insular discipline" (FOURCADE; OLLION; ALGAN, 2015 apud ROBEYNS, 2021, p. 76). Ou seja, "[i]t is tightly managed in a top-down fashion, and there is little engagement with (or simply acknowledgment of) the research done in other social sciences and history" (ROBEYNS, 2021, p. 76). Ao aderir ao método científico tradicional, a teoria neoclássica segue um projeto universalizante, válido para todos, de tal forma que assimila uma única forma de compreender as respostas no ambiente econômico. A economia feminista argumenta que essa postura representa uma barreira epistêmica ao aprimoramento da ciência e suas considerações sensíveis às mulheres e outros grupos sociais. Essa posição é compartilhada pela AC (ROBEYNS, 2021; FERNANDEZ, 2008).

Já em relação ao critério da interseccionalidade e diversidade humana, ou seja, análises que têm em conta as diferenças por classe, raça-etnia e outros fatores, Robeyns (2021) enfatiza que a AC pode ser extremamente útil à abordagem da provisão social, pois dispõe de ferramentas conceituais que levam em conta esses critérios. A AC considera tanto as diferenças interindividuais que podem ser dadas de forma aleatória quanto as diferenças entre os grupos que fazem com que as pessoas vejam a si mesmas ou sejam percebidas por outros como membros de grupos baseados em gênero, raça, etnia, idade, classe social, casta, status de deficiência, idioma, nacionalidade. Isso permite que a AC tenha uma natureza multidimensional, enfoque este cumprido pela pluralidade de funcionamentos e capacitações como importantes espaços avaliativos. Ao dispor de um amplo conjunto de dimensões, a base informacional das avaliações é alargada, o que permite incluir dimensões que podem ser importantes para certos grupos, mas nem tanto para outros (ROBEYNS, 2003, 2021).

Concernente ao critério de análise de processos econômicos, políticos e sociais e de relações de poder, Robeyns (2021) argumenta que a AC pode apresentar alguns desafios e armadilhas à abordagem da provisão social. Ao passo que a AC é capaz de incluir uma análise desses processos econômicos, políticos e sociais, a depender dos objetivos do estudo em questão, tal aderência não é garantida quando se trata das relações de poder. Embora a diversidade humana seja uma noção central na AC, ela pode ser desenvolvida de maneiras diferentes, e algumas teorias sociais são relativamente ingênuas quanto às 
diferenças de poder na sociedade e entre grupos, o que pode tornar a análise das relações de poder insuficientemente robusta. Ao adotar, por exemplo, uma versão feminista versus uma versão mais conservadora sobre as "diferenças de gênero", há impacto nos resultados de desigualdades de gênero em funcionamentos causadas, por exemplo, pela divisão sexual do trabalho remunerado e não remunerado. A questão principal apontada por Robeyns (2021) é quão rica ou superficial é a descrição de gênero e de outros grupos sociais e se tal definição é sensível aos vínculos de poder.

O caráter não especificado da perspectiva de Sen $(1999,2001,2010)$ pode ser um problema para questões envolvendo as mulheres; qualquer avaliação que a AC permite fazer, seja quanto a desigualdade, ao bem-estar, ou a pobreza, é dependente das capacitações que, por sua vez, endossa, implícita ou explicitamente, teorias sociais adicionais, além de considerar uma teoria normativa de escolha. Dependendo da teoria social usada como referência para definir as capacitações, os resultados normativos podem ser bastante divergentes. Se a teoria social for racista ou homofóbica e sexista, a avaliação das capacitações será impactada de acordo com o que essa teoria defende. Uma grande preocupação das feministas é que a AC é vulnerável a interpretações e aplicações androcêntricas (ROBEYNS, 2003), tanto que Staveren e Gasper (2002) entendem que a abordagem fornecida por Nussbaum pelas capacitações concretas oferece uma imagem mais rica e equilibrada da questão do gênero e de suas influências no bem-estar das mulheres.

Quando menciona esse último critério, Power (2004) também se refere à agência humana. Na AC a base informacional é expandida ao formular o bem-estar em termos de funcionamentos e capacitações que permite incluir a agência humana e a agência das mulheres. A agência pode ser compreendida como a habilidade de alguém em definir seus próprios objetivos e agir de acordo com eles e, por isso, importante para o exercício da agência é ter uma compreensão dos próprios valores, bem como ter autoestima, confiança e aspirações. A agência pode ser promovida, por exemplo, por meio de programas e políticas que forneçam treinamentos e habilidades para mulheres e meninas, que expandam suas oportunidades econômicas e sociais, que promovam proteção social levando em conta uma perspectiva de gênero e aumentam o acesso à educação de qualidade. Em termos de capacitações, a agência é expressa quando uma pessoa é livre para ser, fazer e buscar quaisquer objetivos ou valores que considere importantes, ou seja, é a liberdade de transformar as potencialidades em funcionamentos alcançados (GAMMAGE; SMITH, 2017; 
KLUGMAN, et al, 2014 apud GAMMAGE; SMITH, 2017; GAMMAGE; KABEER; RODGERS, 2015).

A identidade e o gênero afetam a agência de uma pessoa, tal qual as estruturas coletivas de restrição plasmadas na sociedade, disponíveis para as pessoas por meio do padrão de regras, normas e preferências, que as distribuem em uma hierarquia social conforme suas identidades intersecionais (FOLBRE, 1994 apud GAMMAGE; SMITH, 2018). A forte tradição em economia feminista em identificar agência segundo o contexto de restrições estruturais não se acomoda ao individualismo metodológico que caracteriza a teoria econômica neoclássica. Nesta, a agência é concebida segundo a ideia de maximização da utilidade individual sujeita a circunstâncias pessoais e restrições orçamentárias. Essa posição, porém, se alterou ao longo do tempo, à medida que o reconhecimento de que a tomada de decisão é um processo frequentemente realizado entre indivíduos e não apenas por eles, e que esses mesmos indivíduos estão posicionados de forma diferente em sua capacidade de levar a cabo o processo de tomada de decisão. As abordagens teóricas dos jogos, por exemplo, foi um campo que incorporou essas inovações (GAMMAGE; KABEER; RODGERS, 2015).

Segundo Kabeer (2021), o conceito de agência humana é central para a análise feminista e análise da desigualdade social, pois chama atenção para como as restrições estruturais moldam a distribuição das opções de meios de subsistência disponíveis para grupos de homens e mulheres. É também central para a agenda de justiça social, porque impulsiona os processos de transformação estrutural. Kabeer (2021) defende três maneiras inter-relacionadas da conceitualização de agência na economia feminista. A primeira delas é pelo conceito de capacitações de Sen. A segunda é pelo conceito de empoderamento que desloca a análise do poder da perspectiva dos grupos dominantes para formas de agência exercidas pelos grupos oprimidos. Kabeer (2021) tem seu próprio conceito de empoderamento que parte da ideia de poder como a habilidade de fazer escolhas. Referese aos processos pelos quais a habilidade de fazer escolhas é adquirida por aqueles em que tal habilidade tenha sido anteriormente negada. A agência feminina leva ao empoderamento quando seu exercício questiona, desafia ou muda normas e instituições regressivas que conservam a subordinação das mulheres (HANMER; KLUGMAN, 2016). E como Power (2004, p. 10) apontou "well-being requires empowerment and choice as well as food and shelter".

O terceiro elemento apontado por Kabeer (2021) é o conceito de cidadania, importante para a agência individual, porque possibilita adentrar as formas coletivas de agência que 
almejam enfrentar as estruturas de injustiça em relação ao gênero. A motivação de Kabeer (2021) em abordar cidadania passa pelo fato de que a agência individual, embora implantada estrategicamente, raramente desestabiliza desigualdades estruturais mais amplas. As mulheres que se recusam a aceitar salários mais baixos do que os dos homens podem estar se posicionando contra práticas de desigualdade de gênero, mas não mudam a injustiça de gênero institucionalizada no mercado.

O último tópico de complementaridade entre a $\mathrm{AC}$ e a economia feminista é quanto aos direitos humanos. Os direitos humanos podem ser entendidos como um arcabouço alternativo, avaliativo e ético para analisar políticas e resultados econômicos. Os objetivos que ressoam na garantia de justiça social são expressos em termos de realização dos direitos, não apenas civis e políticos, mas também econômicos, sociais e culturais. A ideia de que todos os seres humanos têm direitos fundamentais é observada em documentos como a Magna Carta (1774), a Declaração da Independência dos Estados Unidos (1776) e a Declaração dos Direitos do Homem e do Cidadão (1789). A Declaração Universal dos Direitos Humanos de 1948 foi a responsável por lançar as bases do sistema moderno de direitos humanos e, desde então, foi esculpida em vários tratados e declarações, tais como a Convenção sobre a Eliminação de todas as Formas de Discriminação contra as Mulheres (CEDAW, em inglês) (1979) e o Pacto Internacional sobre Direitos Econômicos Sociais e Culturais (1966) (BALAKRISHNAN; HEINTZ, 2021). A abordagem dos direitos humanos permite uma interação complexa entre direitos individuais, direitos coletivos e ação coletiva, e oferece à economia feminista uma linguagem ética amplamente aceita para avaliar as políticas econômicas (BALAKRISHNAN; HEINTZ, 2021).

O Estado tem a responsabilidade primária de respeitar, promover e cumprir os direitos; outras instituições da sociedade, como os mercados e organizações da sociedade civil, também desempenham papel na promoção dos direitos. Uma questão essencial para essa abordagem é a ideia de liberdades individuais substantivas, ou seja, "what people can do and become in the course of their lives" (BALAKRISHNAN; HEINTZ, 2021, p. 82). A abordagem dos direitos humanos e AC compartilham muito em comum: a primeira vai além do foco nas próprias capacitações e enfatiza um processo de raciocínio público pelo qual algumas capacitações são elevadas ao status de direitos. A sustentação dessas liberdades é uma responsabilidade coletiva, exercida por meio do Estado e da cooperação entre os Estados. Porém, é necessária ação coletiva para que as pessoas reivindiquem e participem da realização de seus direitos e responsabilizem governos ao sinal de desrespeito aos direitos garantidos (BALAKRISHNAN; HEINTZ, 2021). 
A abordagem dos direitos humanos é indispensável para a economia feminista porque enfatiza o princípio de não discriminação e igualdade, chamando atenção para as desvantagens e vulnerabilidades específicas com base na identidade. A estrutura de direitos humanos também reconhece a necessidade de igualdade substantiva, além da igualdade formal e legal, e que a consideração de todos os aspectos da vida das pessoas é de suma importância para que todos gozem de direitos idênticos. A ênfase se dá em relação à igualdade de oportunidades e de resultados alcançados. A AC contribui com os fundamentos éticos dos direitos humanos e representa um instrumental analítico capaz de capturar as liberdades e oportunidades que estão ao alcance de uma pessoa - conjunto capacitário -, e as variáveis subjacentes que explicam esse conjunto, tais como variáveis contextuais, fatores de conversão e o sistema de direitos (BALAKRISHNAN; HEINTZ, 2021).

A apreciação desses pontos torna a abordagem dos direitos humanos mais rica do que a encontrada na teoria econômica neoclássica, que se baseia primariamente na maximização da utilidade individual, e um importante arcabouço para considerações de gênero. Tratados como a Convenção Internacional sobre a Eliminação de Todas as Formas de Discriminação Racial (CERD) e a CEDAW são exemplos da possibilidade de proteção dos direitos daqueles que, por razões de identidade, como de raça e gênero, podem ser discriminados (BALAKRISHNAN; HEINTZ, 2021). Importante ressaltar que a definição dos direitos humanos ocorrida entre 1945 e 1948 foi alvo de críticas feministas que buscavam confrontar as hierarquias presentes no regime de direitos humanos, especialmente em relação ao fato de que homens e mulheres têm relações diferentes com o Estado. Os direitos, pela perspectiva feminista, não são fixos e imutáveis, são histórico, social, cultural e economicamente dependentes (PARISI, 2017).

Em síntese, a complementaridade na conceitualização de bem-estar na $A C$ e na economia feminista ocorre nos seguintes pontos: 1. defesa de ambas de uma relação entre as necessidades humanas e o mundo; 2. entendimento do bem-estar para além das distribuições agregadas de renda ou riqueza; 3. entender o bem-estar como medida do sucesso econômico e em termos de realização e de liberdade; 4. reconhecimento das diversidades, interseccionalidades e desigualdades nas condições humanas; 5. abrangência em pensar as ações e comportamentos das pessoas em situações dentro e fora do mercado, o que possibilita a consideração das atividades de cuidado e não remuneradas; 6 . possibilidade da análise de processos econômicos, políticos e sociais; 7. consideração da agência humana; 8. consideração de objetivos e valores éticos; 9. consideração dos direitos humanos. 
Por fim, é importante mencionar o alerta de Robeyns (2021) de que não há garantia que todos os usos da AC sejam feministas ou sensíveis ao gênero. A depender da análise, atividades de cuidado e não remuneradas podem estar ausentes, seja em razão da disponibilidade de dados, seja porque a pesquisa é enviesada. Como os estudos em economia feminista devem considerar, dentre outras questões, normas sociais e gênero, se o estudo parte de uma definição de gênero que não envolva indagações como desigualdade e diferenças de poder, a análise resultante não será compatível com os critérios exigidos por um programa de pesquisa em economia feminista. A principal mensagem que Robeyns (2021) deixa é que, apesar da AC ser uma abordagem mais rica, o que atrai os estudos em economia feminista, "one should never treat it [AC] as a blueprint that can easily be applied to all cases equally well [casos em economia feminista]" (ROBEYNS, 2021, p. 78). O compromisso que a AC e a economia feminista compartilham perpassam o entendimento de "always keep a self-reflexive scholarly attitude and keep critically assessing, and if need be revising, the ontological, normative, and methodological presuppositions of our research" (ROBEYNS, 2021, p. 79).

\section{CONSIDERAÇÕES FINAIS}

Depois de Robbins e os subsequentes desenvolvimentos da teoria econômica neoclássica, o bem-estar econômico passou a ser formulado segundo uma função dos níveis de utilidade individual, em que são privilegiadas as propriedades ordinais de ranqueamento das preferências individuais e a impossibilidade de comparação interpessoal de utilidade. É uma forma de análise oposta à visão ética benthamista e utilitarista de bem-estar que defende que a forma instrumental de medir a utilidade é o caminho adequado para formular políticas e leis que maximizem a felicidade geral. A eficiência econômica, a ponte que mantém em equilíbrio a competência dos economistas em oferecer aconselhamento político com base em sua experiência científica e a prevalência da incompatibilidade de julgamentos éticos, passa a ser entendida em termos da otimalidade de Pareto.

Em posição divergente, Sen enumera algumas limitações dessa noção de bem-estar como a atração da soma total da utilidade, a adaptação e o condicionamento mental, a impossibilidade de comparações interpessoais de utilidade, o descaso com os direitos humanos e considerações éticas, e a interpretação utilitarista da racionalidade humana. Com a estrutura de funcionamentos e capacitações, Sen busca vencer essas limitações ao mudar 
o foco dos meios para atingir o bem-estar para os fins humanos e na liberdade de realizar os seres e fazeres. Como visto, essa mudança é importante em razão dos fatores de conversão.

A economia feminista, em sintonia com a AC, se preocupa com a exclusão sistemática e desvalorização de atividades tradicionalmente encabeçadas pelas mulheres e com a concepção unilateral de homo economicus. Ao considerar os modelos neoclássicos de avaliação do bem-estar, nota-se que as utilidades dos indivíduos são funções apenas das mercadorias em sua posse, mercadorias estas que têm um preço relativo. Os bens e serviços existentes dentro do mercado são mais significativos para o bem-estar econômico do que as atividades fora do mercado.

A sintonia entre a AC e a economia feminista em conceitualizar o bem-estar pode ser observada em diferentes pontos: defesa de uma relação entre as necessidades humanas e o mundo; entendimento do bem-estar para além das distribuições agregadas e da renda; abrangência em pensar as ações e comportamentos das pessoas em situações dentro e fora do mercado; reconhecimento das diversidades e desigualdades nas condições. Porém, não há garantia que todos os usos da $\mathrm{AC}$ se aliem aos critérios da economia feminista, seja porque a pesquisa está enviesada, seja porque definições de conceitos importante como gênero sejam ingênuos. Mas, o importante é destacar que ambas as visões se aproximam novamente do pensamento moral e ético ao tratar de bem-estar, fato que ficou no esquecimento dos teóricos do bem-estar.

\section{REFERÊNCIAS}

AGENJO-CALDERÓN, A.; GÁLVEZ-MUÑOZ, L. Feminist Economics: Theoretical and Political Dimensions. The American Journal of Economics and Sociology, v. 78, p. 137-166, 2019.

ANDERSON, E. What is the point of equality? Ethics, v. 109, n. 2, jan. 1999.

BALAKRISHNAN, R.; HEINTZ, J. Human Rights and Feminist Economics. In: BERIK, G; KONGAR, E. (Ed.). The Routledge Handbook of Feminist Economics. United Kingdom: Routledge, p. 81-89, 2021.

BAKER, D. Economists, Social Reformers, and Prophets: A Feminist Critique of Economic Efficiency. Feminist Economics, v.1, n.3, p. 26-39, 1995.

BELTRAME, B.; MATTOS, L. As críticas de Amartya Sen à teoria da escolha social de Kenneth Arrow. Nova Economia, v. 27, n.1, p. 65-88, 2017. 
BENTHAM, J. An Introduction to the Principles of Morals and Legislation. Ontário, Canadá: Batoche Books, 2000.

BERIK, G.; KONGAR, E. The Social Provisioning Approach in Feminist Economics: The unfolding research. In: (ed.). The Routledge Handbook of Feminist Economics. United Kingdom: Routledge, p. 3-21, 2021.

BERIK, G.; RODGERS, Y.; SEGUINO S. Feminist Economics of Inequality, Development, and Growth. Feminist Economics, v. 15, n. 3, p. 1-33, 2009.

COELHO, L. A invisibilidade das mulheres no discurso económico. Reflexão crítica sobre os conceitos de trabalho, família, bem-estar e poder. e-cadernos CES, 14, p. 7-32, 2011.

DAVIS, J. The Theory of Individual in Economics: Identity and Value. London and New York: Routledge, 2003.

DEQUECH, D. Neoclassical, Mainstream, Orthodox, and Heterodox Economics. Journal of Post Keynesian Economics, v. 30, n. 2, p. 279-302, 2008.

FERNANDEZ, B. A Epistemologia de Hugh Lacey em diálogo com a Economia Feminista: neutralidade, objetividade e pluralismo. Estudos Feministas, Florianópolis, v. 16, n. 2, p. 359-385, maio/ago. 2008.

FERNANDEZ, B. Economia feminista: metodologias, problemas de pesquisa e propostas teóricas em prol da igualdade de gêneros. Revista de Economia Política, v. 38, n. 3, p. 584-605, 2018.

GAMMAGE, S.; SMITH, G. Feminist Economics and Agency. In: POFF, D.C.; MICHALOS, A.C. (ed.). Encyclopedia of Business and Professional Ethics, p. 1-5, 2017.

GAMMAGE, S.; KABEER, N.; RODGERS, Y. Voice and Agency: Where Are We Now? Feminist Economics, p. 1-29, 2015.

GARCIA-MORENO, C.; WATTS, C. Violence against women: an urgent public health priority. Bulletin of the World Health Organization, v. 89, n. 1, p. 2-2, 2011.

GRECCO, F. O viés androcêntrico da Ciência Econômica e as críticas feministas ao homo economicus. Temáticas, Campinas, v. 26, n. 52, p. 105-134, ago./dez. 2018.

HANMER, L.; KLUGMAN, J. Exploring Women's Agency and Empowerment in Developing Countries: Where Do We Stand? Feminist Economics, v. 22, n. 1, p. 237-263, 2016.

HAUSMAN, D.; MCPHERSON, M. Economic Analysis, Moral Philosophy and Public Policy. New York: Cambridge University Press, 2006.

KABEER, N. Three Faces of Agency in Feminist Economics: Capabilities, empowerment, and citizenship. In: BERIK, G; KONGAR, E. (ed.). The Routledge Handbook of Feminist Economics. United Kingdom: Routledge, p. 99-107, 2021.

KOLM, S. Teorias Modernas da Justiça. São Paulo: Martins Fontes, 2000. 
MARIN, S.; QUINTANA, A. A transformação marginal na teoria do valor dos primeiros neoclássicos. Cadernos de Economia, Chapecó, v. 19, p. 115-138, 2006.

MARÇAL, K. O lado invisível da economia: uma visão feminista. São Paulo: Alaúde Editorial, 2017.

MATTOS, L. A Natureza Humana e o 'Homem Econômico' Milliano. Estudos

Econômicos, v. 27, n. 1, p. 69-96, jan./abr. 1997.

NAKAI, D. Three Dimensions of Classical Utilitarian Economic Thought - Bentham, J.S. Mill, and Sidgwick. 2012. Disponível em:

https://www.stern.nyu.edu/sites/default/files/assets/documents/con_037042.pdf. Acesso

em: 24 abr. 2021.

NELSON, J. The Study of Choice or the Study of Provisioning? Gender and the Definition of Economics. In: Beyond Economic Man: Feminist Theory and Economics. FERBER, M.; NELSON, J. (ed.), p. 23-36. Chicago: University of Chicago Press, 1999.

NUSSBAUM, M.; SEN, A. (ed.). The Quality of Life. USA: Oxford University Press, 1993.

NUSSBAUM, M. Human Functioning and Social Justice: In Defense of Aristotelian

Essentialism. Political Theory, v. 20, n. 2, p. 202-246, May 1992.

NUSSBAUM, M. Women and Cultural Universals. In: NUSSBAUM. M.: Sex and Social Justice. Oxford and New York: Oxford University Press, p. 29-54, 1999.

NUSSBAUM, M. Women and Human Development: The Capabilities Approach. New York: Cambridge University Press, 2000.

NUSSBAUM, M. Capabilities as Fundamental Entitlements: Sen and Social Justice.

Feminist Economics, v. 9, n. 2-3, p. 33-59, 2003.

NUSSBAUM, M. Creating Capabilities. The Human Development Approach. Cambridge (MA): The Belknap Press of Harvard University Press, 2011.

PARISI, L. Feminist Perspectives on Human Rights. Oxford Research Encyclopedia of International Studies, 2017. Disponível em:

https://oxfordre.com/internationalstudies/view/10.1093/acrefore/9780190846626.001.0001/ acrefore-9780190846626-e-48. Acesso em: 05 out. 2021.

POUW, N.; MCGREGOR, A. An Economics of Wellbeing: What Would Economics Look Like if it were Focused on Human Wellbeing? Institute of Development Studies (IDS), Working Paper, v. 2014, n. 436, 2014.

POWER, M. Social Provisioning as a Starting Point for Feminist Economics. Feminist Economics, v. 10, n. 3, p. 3-19, Nov. 2004.

RICHARD, A. Egalitarianism. The Stanford Encyclopedia of Philosophy (Summer 2013 Edition), Edward N. Zalta (ed.), Disponível em: 
https://plato.stanford.edu/archives/sum2013/entries/egalitarianism/. Acesso em: 29 abr. 2021.

ROBEYNS, I. Sen's Capability Approach and Gender Inequality: Selecting Relevant Capabilities. Feminist Economics, 9:2-3, p. 61-92, 2003.

ROBEYNS, I. Wellbeing, Freedom and Social Justice: The Capability Approach ReExamined. UK: Open Book Publishers, 2017.

ROBEYNS, I. The Capability Approach. In: BERIK, G; KONGAR, E. (ed.). The Routledge Handbook of Feminist Economics. United Kingdom: Routledge, p. 72-80, 2021.

SANDEL, M. Justiça: $O$ que é fazer a coisa certa. Civilização Brasileira. Edição do Kindle, 2015.

SEN, A. Rational Fools: A Critique of the Behavioral Foundations of Economic Theory. Philosophy and Public Affairs, v. 6, n. 4, p. 317-344, 1977.

SEN, A. Utilitarianism and Welfarism. The Journal of Philosophy, v. 76, n 9, p. 463-89, 1979a.

SEN, A. Personal Utilities and Public Judgements: Or What's Wrong with Welfare Economics. The Economic Journal, v. 89, n. 355, p. 537-558, 1979 b.

SEN, A. Sobre ética e economia. 1. ed. São Paulo: Companhia das Letras, 1999.

SEN, A. Desenvolvimento como liberdade. São Paulo: Companhia das Letras, 2010.

SEN, A. Desigualdade reexaminada. Rio de Janeiro: Record, 2001.

SEN, A. Collective Choice and Social Welfare. Expanded Edition. USA: Penguin Books, 2017.

STAVEREN, I.; GASPER, D. Development as Freedom - Contributions and Shortcomings of Amartya Sen's Development Philosophy for Feminist Economics. The Institute of Social Studies, Working Paper 365, 2002.

STIGLITZ, J. Economics of the public sector. 3. ed. Nova York/Londres: W.W. Norton and Company, 1999.

STIGLITZ, J.; SEN, A.; FITOUSSI, J-P. Measuring Economic Performance and Social Progress. Paris: Report by the Commission on Commission on the Measurement of Economic Performance and Social Progress, 2009.

STROBER, M. Rethinking Economics Through a Feminist Lens. The American Economic Review, v. 84, n. 2, p. 143-147, May 1994.

SUZUMURA, K. Introduction. In: ARROW, K. J.; SEN, A. K.; SUZUMURA, K. (org.) Handbook of Social Choice and Welfare. v. 1. UK: Oxford, p. 1-32, 2002. 
TORRES, G. Economia e Moralidade: uma História de Separação. 2015. 51 f. Trabalho de Conclusão de Curso (Graduação) - Departamento de Economia, Universidade de Brasília, Brasília, 2015.

VIZARD, P.; FUKUDA-PARR, S.; ELSON, D. Introduction: The Capability Approach and Human Rights. Journal of Human Development and Capabilities, v. 12, n. 1, p. 1-22, 2011. 